\title{
“THE PATH OF THE COMEDIAN IS ALWAYS GOING TO BE A LONELY ONE": COMEDIANS' MEDIATION BETWEEN FAMILY HUMOUR AND PUBLIC PERFORMANCE
}

\author{
ANASTASIYA FIADOTAVA \\ Junior Research Fellow \\ Department of Folkloristics \\ Estonian Literary Museum \\ Vanemuise 42, 51003 Tartu, Estonia \\ e-mail: anastasiya.fiadotava@folklore.ee
}

\begin{abstract}
The article* presents a study of the use of family humour in public comedy and the mutual influence of family humour and public humour on comedians' performances and everyday life. The interrelations between these domains lie at the level of the content of humour, its format, its performance and the interaction between humour producers and their audience. Family and public humour often overlap and interweave in various ways, especially in the experience of those who engage in humour production both in public and in private spheres.

The study is informed by interviews with UK-based comedians on their family humorous folklore and its interrelation with their public humour performances. The interconnection between public and family humour was identified on several levels: textual, communicative, personal and conceptual.

This multidimensional interplay indicates that family humour is contingent on the context, but at the same time is often conditioned by comedians' public personae and cannot be fully separated from the humour they perform publicly. The study illustrates the vagueness of the dichotomy between public comic performances and family humour and points to multiple ways in which the boundaries between these domains can become blurry.
\end{abstract}

KEYWORDS: humour $\bullet$ comedians $\bullet$ public $\bullet$ private $\bullet$ family

* This research was supported by the European Union through the European Regional Development Fund (Centre of Excellence in Estonian Studies, TK 145), by the Estonian Ministry of Education and Research EKKD65 grant (Source Documents in the Cultural Process: Estonian Materials in the Collections and Databases of the Estonian Literary Museum) and is related to the research project Narrative and Belief Aspects of Folklore Studies (EKM 8-2/20/3, Estonian Literary Museum). I would also like to thank Dr Sharon Lockyer (Centre for Comedy Studies Research, Brunel University London) and my dear friend Dr Maria Zhivitskaya for their support and for putting me in touch with comedians. 
Stand-up comedians, comic book writers, cartoonists and other humourists have the opportunity (and challenge) to constantly balance the border between the private domain of family humour and public humorous performances. While for most people, performing humorous folklore is largely limited to private settings and familiar audiences, comedians perform humour both privately and publicly on a regular basis. This paper presents a pilot study on the interconnections between public comic performances and family humorous communication of professional and amateur comedians. The central goal of the article is to determine how the boundaries between public and family humour are negotiated by those who actively engage in the production of humour in both settings.

Family life and family humour are conceptualised as part of the private sphere of life and are thus juxtaposed with the public domain. However, the dichotomy between public and private is primarily an ideological construct in the sense that it is used as a metadiscursive label to categorise the cultural objects and articulate the distinction between them (Gal 2002: 78-79). As with any other explicit and mutually exclusive categorisation, this dichotomy is frequently challenged by empirical evidence. When we look closely at the topics and forms of family and public humour, we can see that the borders between them are not always clear-cut and often overlap.

On the other hand, the reference to the dichotomy between public comic performances and private family humour is still a useful methodological tool that helps us analyse the comedians' position as mediators between different spheres. It also sheds light on how comedians make decisions about choice of performance material: the content that they categorise as private is not considered appropriate for public performances for various ethical and pragmatic reasons (i.e., wanting to keep what passes between family members confidential or aiming at a more generally recognisable performance). The humour performed in public, as well as the public persona of a humourist, have to follow certain conventions to be accepted by the audience. The paper will explore how these conventions are negotiated in the family setting, and to what extent public and private humour interweave in comedians' lives.

\section{THEORETICAL BACKGROUND AND LITERATURE OVERVIEW}

The theoretical foundations of my research primarily lie in the field of folklore studies. Many of the concepts that are situated at the core of public and private humour have been recurrent keywords in folklore studies: the notions of in- and out-group, performance, text, context and identity are instrumental to understanding how people engage with humour in different settings. I also draw on numerous insights from the interdisciplinary field of humour studies, which has explored public and family humour through various methodological approaches.

The discussion of humour production and appreciation in the context of group communication often revolves around constructing and maintaining group boundaries and a shared identity. Gary Alan Fine (1977; 1979) focused on interactions within small groups, and coined the term 'idioculture' to refer to these groups' communicative 
practices, as well as the term 'idiowit' that denotes the humorous aspects of idioculture (1977: 315). He also emphasised the role of humour in self-presentation and identity construction (Fine 1984). In-group humour can not only define the boundaries of the ingroup, but also comment on and even challenge the power relations within it. It can also reflect the closeness and reaffirm shared perceptions of the past experiences of a group, especially if a groups is small and its members are intimately related (Oring 1984: 21).

The family has been recognised as a particular kind of group in the context of humour use. The affect of the family environment can be seen on the level of humour appreciation (Wilson et al. 1977) and accounts for the existence of family humour styles (Everts 2003). As I have argued elsewhere (Fiadotava 2018; 2020a; 2020c), family humour is always tightly connected to the personal experiences of family members, and its performances add new layers to the relationship between the performer and their audience. Family units share many features with other informal groups (for example, groups of friends) when it comes to humorous communication. However, they also have some distinct features: family members normally spend significantly more time together (both in terms of frequency and duration of communication) and thus encounter many diverse communication settings where they can use humour. Such a dense humorous interaction means that romantic and family couples' perceptions of each other's humour is important for maintaining their relationships (see Alberts 1991, Ziv and Gadish 1989). Therefore, even though humour might be regarded as a trivial matter in family communication, and family members often do not consciously reflect on it, humorous interactions within a family play a vital role in maintaining relations and making sense of shared experiences.

The public aspect of humorous performances that occur outside of families and other informal groups has also been one of the subjects of scholarly research. Giselinde Kuipers (2011) addressed the issue of the politics of humour and the power dynamics of its use in the public sphere by analysing the controversies that arose after the publication of the 'Muhammad cartoons' in Denmark in 2006. This example, along with several other cartoons and a comic impersonation on television, were also discussed by Adrian Hale (2018) in the context of failing high-profile public humour.

The studies of professional and amateur comedians have largely focused on the comedians' routines per se and the ways they are presented (see, for example, Rutter 1997; Greenbaum 1999; Scarpetta and Spagnolli 2009; Brodie 2014, etc.), the personalities of comedians (see, for example, Janus 1975; Greengross 2009; Greengross et al. 2012; Ando et al. 2014, etc.) and the effect of comedy on its audience and society at large (see, for example, Zoglin 2009; Miles 2014; Quirk 2015, etc.). The studies that address the interrelation between comedians' public humour and their private family circumstances are scarcer. This topic was generally raised in the general discussions of stand-up comedians' socio-demographic background (Stebbins 1990: 60-68), the effect of family life on the comedians' personae, repertoire and skills (see, for example, Double 2005) and the ways families feature in their routines (Dore 2018). However, little has been said about the multiple ways comedians' public and family humour can influence each other.

The humour of stand-up comedians is an interesting and ambiguous example of humour that belongs to the public sphere but at the same time incorporates many features of private humour. While Gil Greengross (2009: 6) argues that professional stand- 
up comedians "do not represent mundane occurrences of humour and laughter, but rather exemplify an exaggerated form of public humor", other researchers articulate the boundary between public and private humour in stand-up comedy in a more nuanced way. John Limon (2000: 6) argues that "comedians are not allowed to be either natural or artificial", thus underscoring that stand-up comedy involves constantly shifting between the immediacy of private humour and the 'constructedness' of public comedy. Ian Brodie (2014) in his seminal study of stand-up comedy elaborates on this idea. He points out that stand-up comedians in their performances experience "the tension of someone existing simultaneously outside and inside the group" (ibid.: 69), and standup comedy itself is "an indeterminate place between mediated and intimate cultures" (ibid.: 37). Antti Lindfors (2019b: 17) also discusses stand-up comedians' self-mediation in the public sphere "within a performance form founded on ideals of immediacy, actuality, and self-presence".

This peculiar position of stand-up comedians has mainly been analysed within the context of their performances, but there is also another side to it. Personal experiences that comedians communicate on stage, as well as the very fact that they perform humour publicly, can be reflected in their intimate humorous communication. This study intends to uncover this connection not only by analysing stand-up comedians' experiences, but also by incorporating the perceptions of other people who produce public humour. While stand-up comedians definitely differ from comedy writers and cartoonists because their performances presuppose immediate contact with their audiences, the latter also engage in public humour production and interact with their readers, although in a mediated way. Building upon previous scholarship on the use of humour in public and private spheres, as well as on studies of comedians, I intend to explore how the interrelations between these spheres manifest themselves within particular peoples' experiences.

\section{METHODS AND DATA}

This research is based on ten interviews with UK-based professional and amateur comedians on the role of humorous folklore in their families and its interrelation with their public humour performances. While this was not my initial intention, the gender composition of the interviewees ended up mirroring the uneven gender distribution in comedy (see, for example, Seizer 2011: 221; Marx 2016: 280), with nine male comedians and only one female respondent. Most of my interviewees were stand-up comedians, but the group also included a cartoonist and a comedy writer. ${ }^{1}$ The interviews were conducted in March-April 2019, with eight of them taking place in person (of which seven were in London) and a further two conducted via Skype. The questionnaire (see Appendix) focused on the interviewees' family humorous folklore and was almost identical to the one used in my research on family humour among Belarusian families (see Fiadotava 2020c). I relied on my interviewees' emic understanding of the concept of family; thus, some of them focused exclusively on their nuclear family, while others also discussed the use of humour within their extended families. In addition to asking for comments on the role of humour in their family life and examples of humorous folklore, I was also interested in the intersections between their private family humour and their public performances of humour. 
Each interview took approximately 30-40 minutes and was audio recorded. The interviews were subsequently transcribed and anonymised. After this, the interview texts were subjected to qualitative analysis. I took into consideration the complex accounts of my interviewees' family humour, but for the purposes of the present paper, I paid particular attention to the extracts where they provided their reflections on the intersections between their private and public humour. As a folklorist, I was interested in the emic perspectives and tried to put them at the centre of my analysis. Unfortunately, I did not have a chance to interview comedians' family members, so the empirical part of my study consists only of the reflections of the comedians themselves. However, I also intend to put my research in the broader context of humour performances in public and private interactions, and show the peculiarity of comedians' position as mediators between these two domains.

\section{HUMOUR IN PUBLIC AND PRIVATE COMMUNICATION²}

Making a joke or performing any other kind of humour always presupposes an interaction with an audience; in order for humour to succeed, ${ }^{3}$ its performer has to take into account many factors associated with his or her audience, such as their age, gender, relations between one another and, with the humour performer, the immediate context of the performance, as well as the larger social and cultural context, etc. Even in private communication with a small and familiar audience, it may be not easy to consciously weigh all these factors, but the task becomes exponentially more complicated in the case of public humour. A joke-teller inevitably has to make compromises and take risks when deciding on the content, form and performance of a particular joke.

The content of a humorous utterance has to be both appropriate and incongruent to be recognised - even if not always appreciated - as a joke (Oring 2003). In private settings, much of the humour derives from the personal (shared) experience of joke tellers and their audience (Flamson and Barrett 2008: 264), to the point that it may not be comprehensible to outsiders (Oring 1984). In such settings, the joke target often coincides with the audience; even in the case of more impersonal humorous genres, such as canned jokes, the content may be adapted to fit the context of a particular small group (see for example Fiadotava 2018). In contrast, public humorous communication does not, in most instances, provide this opportunity for personal adaption, although the content of public humour also targets and therefore reflects a particular audience (cf. Kuipers 2011: 73). This becomes particularly evident in the case of such ambiguous and contested spheres as political and ethnic humour, which can sometimes involve actual risk for joke tellers and/or their audiences (Oring 2004).

The format of private and public humour also illustrates the fluidity of these two categories. Private humour is to a large extent conversational and thus highly diverse in its forms: different genres interweave and create a pattern suitable for a particular communicative event. Moreover, private humour tends to be economical in its form, with long narratives often being replaced by 'kernel' stories (Kalcik 1975) that evoke specific memories. Some genres of public humour also come close to private communicative forms (see for example Brodie 2014 for the discussion of stand-up comedy as a form of small talk). Other genres, such as comedy plays or cartoons, are more rigidly 
structured. They can mimic some aspects of private communication, but they lack its immediacy and rootedness in the shared experience of its members. However, both private and public humorous communication has to take into account the tastes of the audience: not only in terms of content, but also in terms of genre (Kuipers 2006).

Finally, there are certain differences pertaining to the performative dimension of humour in private and public contexts. The main difference relates to agency distribution between the members of the interaction. In an informal conversation between family members or friends, participants enjoy a more equal status in terms of humour production and performance compared to the audience of a stand-up comedy show (Lindfors 2019a; 2019b), let alone the readers of a comic book or viewers of a humorous cartoon. Performers in private and in public settings also face different expectations. In the case of public humour, the audience evaluates not only a particular humorous instance, but also the stand-up comedian's expertise in delivering his or her routine, a writer's ability to master style, or a cartoonist's skill in drawing characters. In contrast, in private humorous interactions, the audience mainly evaluates only the jokes per se, rather than expressing any judgements about the joker (Bell 2009).

The differences outlined above may not, however, be as straightforward when it comes to people who employ humour in both spheres, with the interplay between public and private humour often becoming ambiguous. Indeed, while some of my informants attempted to distance their family humour from their public engagement with comedy, others argued that it was not possible to draw a clear boundary between the two. The interconnection between public and family humour can be identified on several levels: textual (how the comedians adapt their family humour to their public performances), communicative (how being a comedian affects communication with family members), personal (how family members evaluate comedians' personalities during private humorous interactions) and conceptual (how the status of comedian influences the understanding of the notion of humour). These levels are mutually dependent and overlapping, but each of them opens up a specific dimension of comedians' use of humour.

\section{Textual Level}

My interviewees highlighted the discrepancy between their private jokes and their stage jokes, comedy writing or drawings. Many of them emphasised that while they actively use humour both in public and in family communication, humorous items do not travel between the two domains. Moreover, private and public humour can to some extent be regarded as mutually exclusive. Describing his humorous communication with his partner, one of my interviewees mentioned:

We feel that it's [public and family humour], like, separate... Okay, maybe sometimes I tell a story, and she laughs, and I think: “Oh, this might be funny, it might become a joke". But the moment it becomes a joke on stage, it's not our private joke anymore. (FM: male, 42 years old)

Such clear differentiation between the jokes delivered publicly on stage and those enjoyed in a family circle might reflect the desire to keep one's private life and public 
life separate. Moreover, the discrepancy between public and family humour often has to do with the amount of context necessary to appreciate a certain joke. Appreciation of family humour (as well as any other type of inside humour) requires a lot of contextual knowledge, but this knowledge is not verbalised during the act of joke-telling; instead, it is assumed that the interlocutors are able to actualise it in their memories without it being explicitly evoked. Conversely, the audience of a stand-up performance, while usually sharing some basic cultural knowledge with the performer, is not necessarily familiar with their personal background, especially when the comedian is new to the field (cf. Brodie 2014: 88). The comedian thus has to introduce this background in as brief and funny a way as possible:

I'm having to explain 20-30 years' worth of experience as to why something would cause someone to smile, whereas they [family members] don't need the explanation, it's just their life. [...] Whereas sometimes when you're on stage, you try to find the quickest way to the punchline, 'cause you haven't got time for 20 years' worth of explanation. So in many times you have to be, let's say for a better word, economical with the truth. So sometimes, rather than being a story of three uncles, you'd merge it into one uncle... Rather than it be a story that occurred over 20 years, you'll turn it into the afternoon. [...] And so to make it funny on stage, the audience just needs to [understand] quickly: "It's an uncle, it's an afternoon, and this happens". Whereas [in] the actual story it's three different people, it's 10 years of things [...] and 5 different things happened, but you are just picking the funniest one. (FM: male, 43 years old)

I think for something to be considered an inside joke, it would, it almost needs to be so decontextualised from the original thing that you like, the original context doesn't appear anymore, and so it would take a very long time to explain on stage. (FM: male, 36 years old)

Another key issue that comedians face when trying to translate their family humour for public performance is ethics. Comedians' family members can be easily recognised and identified in their performances; transforming them into the characters of a stand-up routine, comic novel or humorous cartoon inevitably involves publicity and creates a certain typified image of them for the comedian's audience. Margherita Dore (2018: 116) argues that "the butt of these jokes [about family and friends] falls outside the comedian-audience relationship; hence, this distance allows both parties to freely express their sense of superiority by laughing at the targets of the humor" ${ }^{4}$ However, even if the constructed image is not negative, the family members in question and comedians themselves may feel uneasy about using private family humour on stage (Double 2005: 104-105). The issue becomes especially acute when family members are present in the audience and are easily identifiable. While some of my interviewees preferred to stay on the safe side by avoiding any mention of their family members in their performances, others used different strategies to mitigate these ethical considerations.

They both [the interviewee's sons] have type 1 diabetes and I decided to do a show about the experience of bringing up kids with type 1 diabetes. I've never really done anything that ambitious before. So a lot of the show is about them. [...] It's interesting, because after I did that, I then went on to perform a kind of version of 
this show for a diabetes organisation. And quite often that was at events aimed at families affected by diabetes. And the boys [his sons] would be there. And they would be talked about on stage. And apparently sometimes people would slightly make fun of them when they're off playing with their fellow kids. So I completely got it right. But, you know, that's quite a long history of comedians talking about people, real people in their lives. And you know, sometimes, not always those people are happy about that. Well, obviously it's particularly with your own children, you are always trying to get it right. I do try! I don't really talk about them much on stage anymore. I might tell the odd, you know, story about something that happened years ago. But normally if I do that now, the point of the story will be more about me than about them. Like they might just be side characters in it, that sort of thing. (FM: male, 53 years old)

The example above reflects the interviewee's conflicting emotions about discussing his children in his stand-up routine. On the one hand, he acknowledges his own efforts (as well as the efforts of his fellow comedians) to try to strike a balance between humour and ethics. On the other hand, he acknowledges that he still ended up shifting the focus from his family members towards self-presentation (on stand-up comedy as self-presentation see, for example, Lindfors 2019a; 2019b).

The tension between ethics and willingness to make fun of one's family can also be renegotiated on an extra-textual level, for example, by giving them greater agency and involving them in the performance more directly:

And I took the chance to do [...] the routine about the jokes, the conversational jokes of my father and so the $\mathrm{MC}$ in the end offered five minutes to my father. It was a joke, of course, but so that was a nice way to make them [interviewee's parents], at least to make him [his father] a part of it, instead of doing just comedy about them, instead of laughing at them, it was laughing with them, which was nice. (FM: male, 49 years old)

Regardless of whether they incorporate their private humour in their public performance, comedians often reflect on jokes' transformations when they travel between the two domains. These transformations have to do with comedians' differing relationships with the two kinds of audience: the transitory, contingent, asymmetric relationship they have with comedy-goers and the deep, lasting, intimate bond they have with their families.

\section{Communicative Level}

Not only does private humour sometimes make its way into comedians' public performances, but the reverse is also true: public engagement with humour may also have a certain effect on the comedian's family humour. One of my interviewees recalled the following episode which serves to illustrate this point:

I used to work with a comedian called Billy Johnson [pseudonym], he was a very funny character, so I've talked about it a lot with my wife and daughter, and we have little kind of running jokes about things that he might have said. (FM: male, 53 years old) 
However, such direct borrowings from public into private communication were rarely mentioned. Public involvement in comedy tends to manifest itself not at the level of the content of family folklore, but rather at the level of the modalities of communication. Given that stand-up comedy elevates the everyday presentation of self (Goffman 1959) into the public sphere (Brock 2015: 43), it is natural that stage personae and modes of communication can also be reflected in comedians' daily routines and family interactions. However, references to public comic personae are mainly implicit and manifested through family members' ways of addressing the comedian. In some cases, this interference of the public sphere with private communication can lead to challenges for a comedian.

And it's funny, because being a comic, people often think if you are a comedian, you are open to constant abuse. And that you are ready to combat this with any kind of joke, any kind of line. I guess it's like if you are a medic people also tend to tell you they are sick. If you are a comedian, people constantly try to take you on, try to get you to sort of, try to fire something at you, that you... because that's what we do. [...] And I don't want it in my personal life, actually, it's the last thing I really want. (FM: female, 49 years old)

In the quote above, the cause of the interviewee's frustration lies on two levels. First, the intrusion of her public persona into her private life creates certain tensions and leads to her being the target of a disproportionate amount of aggressive humour (compared to the way it could have been if her occupation were not related to comedy). Second, earlier in the interview the same comedian mentioned her dislike for aggressive humour in general and preference towards affiliative jokes, and contrasted this to her mother's preferences in family humorous communication.

However, being a comedian can also affect family interactions in a positive way. Several interviewees testified that their comic work made them more confident in telling jokes in the family setting and generally benefited their storytelling skills. Similarly to performing gigs on stage, joke-telling in everyday settings "gives expression to personality because joke telling demands an involvement of self" (Bronner 1984: 35) and involves attention management. The experience of being a comedian proved to be especially relevant in the performance of narrative humorous genres, while puns and other forms of wordplay were not mentioned in this context. Neither did my interviewees display much interest in telling canned jokes. Moreover, one of the interviewees explicitly emphasised his reluctance to use this folklore genre: "I'm not a great fan of canned jokes. I like jokes to be [the] fruit of my mind, my weird way of looking at things. Comedians usually don't like canned jokes, because they are canned, they are too stale." (FM: male, 49 years old)

Not only does this interviewee express his attitude towards canned jokes, but he also makes an attempt to extrapolate his personal preferences to a more general level of humorous communication. Such projections were not uncommon in my interviewees' responses. For example, another interviewee describes her frequent use of humour in family interactions by noting that "if you are a comic, you just naturally insert a punch" (FM: female, 49 years old). Thus, another effect of involvement in the sphere of public humour on family interaction is some comedians' tendency to constantly shift the modality of communication to the humorous. Comedians' frequent reliance on humour 
to reframe their interactions as playful (Norrick 1994: 411) can fulfil various functions in their interpersonal communication (for an overview see, for example, Graham et al. 1992; Ziv 2010). Moreover, by using humour in private settings, comedians can (in)voluntarily refer to their public personae, thus extending the interrelation between public and private humour to the personal level.

\section{Personal Level}

Despite many comedians' best efforts to keep their comic personae separate from their private lives, their family members might still include references to their humourrelated public activities in private interactions. Even those who engage in comedy on an amateur level mentioned frequent references to their hobby in conversations with family members. The references are often triggered by use of humour in such conversations and revolve around comedians' perceived 'funniness':

If I say something funny, they mock me for not being funny. You know what I mean? Since it's my job. "Oh, you should be in comedy!" [...] So they always draw attention if I make a really awful joke that doesn't work, or wasn't funny. (FM: male, 59 years old)

Every time I crack a joke, she [the interviewee's partner] always, she laughs, and then she tries to mock me: "Come on, you are a comedian, I expect something better!" or she comments on how long it took me to come up with a joke since whatever happened. (FM: male, 49 years old)

Nancy Bell (2009: 1830) suggests that when humour fails, it is generally more common to react with an evaluation of the joke rather than the-joke teller, in order to prevent a greater face-threat and maintain social harmony. Yet, when the failed humour has been produced by a comedian, the negative evaluation of the joke is more likely to be accompanied by reflection on their engagement in comedy as well. In fact, this reflection does not even require the joke to fail: irony or mockery can be triggered by the very act of making a joke, even if the joke works (i.e., is met with laughter). The overlap between public and private spheres thus creates a fruitful basis for meta-humorous commentary.

An interesting aspect of this is the (presumed) symbolic authority of the comedians in the domain of humour, which gives them the power to judge what is funny and what is not. This is closely connected to the evaluative aspect discussed above, since a reference to the comedian's superior expertise in the domain of humour production and appreciation is one of the tactics used to mitigate the consequences of failed humour. This reference itself can be framed in a humorous manner, thus indicating comedians' awareness of the vagueness of the category of 'expert' in the sphere of humour and their willingness to engage in self-reflection, which is an integral part of their trade (Lindfors 2019a; 2019b):

And even up to a point when I would tell a joke that's not really funny, I will say something that's not really funny, and then my daughter may go like: "Dad, that's not really funny". And I'd go: "Look, I'm a comedy writer, [...] you know, let me decide what's funny, not you, you don't know..." Things like that. So we kind of joke about that. (FM: male, 53 years old) 
Comedians' family members can also perceive humorous communication with them from another angle: that of the audience of a public comedy show. Even though I did not have an opportunity to interview comedians' family members for the present study, some of the stand-up comedians I spoke with mentioned that their family members occasionally suggest testing the comedians' material on them. While trying out stage material on a small group of people is problematic - especially in the case of stand-up comedians, whose success or failure, perhaps even more than that of other performance artists, relies on audience interaction and crowd dynamic - the fact that family members make this suggestion at all points to another overlap between family and public communication, and shows how the latter can have an effect on the former. The family members' reaction to a humorous utterance is conditioned to a certain extent by their awareness that this utterance may breach the boundaries of their private communication and be appropriated by a wider audience. Being, or even imagining they can be, an 'exemplary audience' also entails a certain responsibility and presupposes engagement with humour on a more profound conceptual level, whereby the family members must assume the role of an audience that could be quite different from them in terms of demographics and humorous preferences.

\section{Conceptual Level}

Several of my interviewees pointed out that being a comedian (or even a comedian's family member) necessitates a better understanding of the nature and mechanisms of humour, which leads to a re-evaluation of the role of humour in family communication. As with any other domain, comedy requires certain competences and skills; understanding the mechanisms of humour production and appreciation are certainly among the most crucial of them. While being aware of the mirthful aspect of comedy, some of my interviewees also pointed out its other side: "Apart from that, I am aware of the negative side of comedy, I think. I am aware that it could be really hurtful and destructive. Because it's quite powerful, it can be quite a destructive thing." (FM: male, 59 years old)

Side by side with understanding the negative potential of comedy comes an awareness of the dark side of the comedic profession. Although the popular image of "a sad clown behind a happy mask" must be taken with a pinch of salt (Double 1997: 254-255), it is a recurrent perception not just in popular culture but also in academic discourse. Simon Steward and David Thompson's (2015) research has even suggested that the very features that condition comedians' popularity contribute to their reduced longevity. This perception of comedians was also mentioned by several interviewees: "There are a lot of really miserable comedians, apparently. You know, who are miserable and don't have their own lives." (FM: male, 59 years old)

...[N]ow my fiancée tells me, because she gets to know some comedians through me, and sometimes comedians get to be a bit sad or depressed in their private life, and apparently I'm not, so she's surprised that I'm trying to be funny, that I try some light, private jokes. (FM: male, 42 years old)

However, as this quote illustrates, when referring to other comedians' perceived unhappiness and propensity for depression, my interviewees made it clear that this does not 
apply to themselves. By separating their own experience from the general tendency (debatable though the tendency is), comedians construct a more abstract category of 'humourist' and explore the interrelation between the public and the private on an impersonal level.

\section{CONCLUSION}

The account above is by no means an exhaustive overview of how the interconnection between public and family humour manifests itself in comedians' lives. Yet, it does point to multidimensional interplay between the two domains and indicates that, while private folklore is very much contingent on context, it is often still conditioned by comedians' public personae and cannot be fully separated from the humour they perform publicly (Willis 2005: 134-135). By renegotiating various aspects of humour production and appreciation, comedians act as mediators not only of "cultural codes" (Paton et al. 1988: xv), but also of different modalities of life.

The interaction between family and public humour is far from being unidirectional. On the one hand, comedians' public identities may sometimes condition the content and form of their private humorous performances, as well as the attitude of their family members towards their humorous utterances. On the other hand, family humour also influences how and what comedians perform, write or draw for a wider audience. Indeed, personal background and the patterns of family humorous communication often lie at the core of a comedian's public humour. Even when these aspects are not made explicit to the audience, they are subject to comedians' self-reflection.

Reflexivity is another important feature of professional and amateur comedians' attitudes towards their family humour. Having constantly to see "oneself as others see one" (Lindfors 2019a: 5) in the sphere of public humour, they extrapolate this approach to their family humour and engage with it critically in their family discussions and in their private contemplations.

The extent to which public humour pervades the private sphere (and the other way around) depends to a great extent on the particular circumstances of a given family and on the repertoire of the comedian's public humour. While it might be difficult to separate one's public and private lives - and humour - completely, it is often up to the comedians and their family members to decide where the boundary lies, and whether that boundary must always be upheld.

The four levels of interrelation between public and family humour that were discussed in this paper - textual, communicative, personal and conceptual - are mutually dependent and interweave in various ways. The conceptual level serves as an overarching theoretical framework of comedians' self-reflection and self-presentation, whereas the textual, communicative and personal levels refer to different spheres of their performative practices. As comedians themselves, their family members and their audiences often find it difficult (and unnecessary) to separate their texts and communication styles from their personalities, and thus refrain from maintaining the clear distinction between their public and private lives.

Comedians' peculiar situatedness at the intersection between public and private humour puts them at the crux of this dichotomy. At the same time, a study of their per- 
spectives on the different domains of humour cannot contribute to making the boundaries of this dichotomy clearer. On the contrary, it serves to problematise and highlight the vagueness of this social construct, illustrating ways how the boundaries between public and private humour can become fuzzy in a multitude of ways. The particular context of Great Britain might also account for the results of this study: future comparative research could shed light on whether these interconnections between public and private humour are universal or culture-specific. The interconnections between public and private humour can thus be viewed as a multidimensional continuum within which different families and individuals negotiate their humorous communication.

\section{NOTES}

1 I will be using the umbrella term 'comedian' to refer to all of them from here onwards.

$2 \mathrm{~A}$ part of this chapter was published as a part of my PhD thesis (Fiadotava 2020b).

3 The success of a joke typically involves eliciting laughter from the audience, but in some cases the joke teller might pursue the opposite goal: to provoke unlaughter (for a discussion on unlaughter, see Billig 2005: 192; Smith 2009). Intentional provocation of unlaughter is more typical of public rather than private humour (Marsh 2015: 79-84).

4 For a prominent example of incorporating family members, including as joke targets, into a stand-up performance, see Titus 2004.

\section{SOURCES}

$\mathrm{FM}=$ fieldwork materials of the author.

\section{REFERENCES}

Ando, Victoria; Gordon Claridge and Ken Clark. 2014. Psychotic Traits in Comedians. - The British Journal of Psychiatry 204 (5): 341-345. DOI: https://doi.org/10.1192/bjp.bp.113.134569.

Alberts, Janet K. 1991. The Use of Humor in Managing Couples' Conflict Interactions. - Intimates in Conflict: A Communication Perspective, edited by Dudley D. Cahn. London: Routledge, $105-120$.

Bell, Nancy D. 2009. Responses to Failed Humor. - Journal of Pragmatics 41 (9): 1825-1836. DOI: https://doi.org/10.1016/j.pragma.2008.10.010.

Billig, Michael. 2005. Laughter and Ridicule: Towards a Social Critique of Humor. Thousand Oaks: Sage.

Brock, Alexander. 2015. Participation Frameworks and Participation in Televised Sitcom, Candid Camera and Stand-up Comedy. - Participation in Public and Social Media Interactions, edited by Jan Chovanec and Marta Dynel. Amsterdam; Philadelphia, PA: John Benjamins Publishing Company, 27-47. DOI: https://doi.org/10.1075/pbns.256.02bro.

Brodie, Ian. 2014. A Vulgar Art: A New Approach to Stand-up Comedy. Jackson, MS: University Press of Mississippi. DOI: https://doi.org/10.14325/mississippi/9781628461824.001.0001.

Bronner, Simon J. 1984. "Let Me Tell It My Way": Joke Telling by a Father and Son. - Western Folklore 43 (1): 18-36. DOI: https://doi.org/10.2307/1499427. 
Dore, Margherita. 2018. Laughing at You or Laughing with You? Humour Negotiation and Intercultural Stand-up Comedy. - The Dynamics of Interactional Humor: Creating and Negotiating Humor in Everyday Encounters, edited by Villy Tsakona and Jan Chovanec. Amsterdam; Philadelphia, PA: John Benjamins Publishing Company, 105-126. DOI: https://doi.org/10.1075/ thr.7.05dor.

Double, Oliver. 1997. Stand Up: On Being a Comedian. London: Methuen Drama. DOI: https://doi. org/10.5040/9781408162811.

Double, Oliver. 2005. Getting the Joke: The Inner Workings of Stand-up Comedy. London: Methuen Drama.

Everts, Elisa. 2003. Identifying a Particular Family Humor Style: A Sociolinguistic Discourse Analysis. - Humor - International Journal of Humor Research 16 (4): 369-412. DOI: https://doi. org/10.1515/humr.2003.021.

Fiadotava, Anastasiya. 2018. Cooking with Humour: A Study of Belarusian Humorous Folklore about Family Cooking Traditions. - Folklore. Electronic Journal of Folklore 71: 89-112. DOI: https://doi.org/10.7592/FEJF2018.71.fiadotava.

Fiadotava, Anastasiya. 2020a. Sharing Humour Digitally in Family Communication. - European Journal of Humour Research 8 (1): 95-111. DOI: https://doi.org/10.7592/EJHR2020.8.1.fiadotava.

Fiadotava, Anastasiya. 2020b. Family Humour in Contemporary Belarus: Forms, Practices and Vernacular Reflections. Phd Dissertation. University of Tartu. https://dspace.ut.ee/handle/10062/68369 (accessed September 8, 2020).

Fiadotava, Anastasiya. 2020c. "If We Don't Quarrel, We Joke": Emic Perspectives on Belarusian Families' Humorous Folklore. - Humor - International Journal of Humor Research. DOI: https:// doi.org/10.1515/humor-2019-0052.

Fine, Gary Alan. 1977. Humour in Situ: The Role of Humour in Small Group Culture. - It's a Funny Thing, Humour, edited by Antony J. Chapman and Hugh C. Foot. Oxford; New York, NY: Pergamon Press, 315-318. DOI: https://doi.org/10.1016/B978-0-08-021376-7.50060-7.

Fine, Gary Alan. 1979. Small Groups and Culture Creation: The Idioculture of Little League Baseball Teams. - American Sociological Review 44 (5): 733-745. DOI: https://doi.org/10.2307/2094525.

Fine, Gary Alan. 1984. Humorous Interaction and the Social Construction of Meaning: Making Sense in a Jocular Vein. - Studies in Symbolic Interaction 5: 83-101.

Flamson, Thomas and H. Clark Barrett. 2008. The Encryption Theory of Humor: A Knowledgebased Mechanism of Honest Signaling. - Journal of Evolutionary Psychology 6 (4): 261-281. DOI: https://doi.org/10.1556/JEP.6.2008.4.2.

Gal, Susan. 2002. A Semiotics of the Public/Private Distinction. - differences: A Journal of Feminist Cultural Studies 13 (1): 77-95. DOI: https://doi.org/10.1215/10407391-13-1-77.

Goffman, Erving. 1959. The Presentation of Self in Everyday Life. New York, NY: Anchor; Random.

Graham, Elizabeth E.; Michael J. Papa and Gordon P. Brooks. 1992. Functions of Humor in Conversation: Conceptualization and Measurement. - Western Journal of Communication 56 (2): 161-183. DOI: https://doi.org/10.1080/10570319209374409.

Greenbaum, Andrea. 1999. Stand-up Comedy as Rhetorical Argument: An Investigation of Comic Culture. - Humor - International Journal of Humor Research 12 (1): 33-46. DOI: https://doi. org/10.1515/humr.1999.12.1.33.

Greengross, Gil. 2009. In Search of Homo Humorous: Personality, Health, Humor Styles and Humor as a Mental Fitness Indicator in Stand-up Comedians and the Rest of Us. PhD dissertation. The University of New Mexico. https://search.proquest.com/openview/726adbd24c827f3586b bfef563b5ca39/1?pq-origsite=gscholar\&cbl=18750\&diss=y (accessed June 1, 2020).

Greengross, Gil; Rod A. Martin and Geoffrey Miller. 2012. Personality Traits, Intelligence, Humor Styles, and Humor Production Ability of Professional Stand-up Comedians Compared to College Students. - Psychology of Aesthetics, Creativity, and the Arts 6 (1): 74-82. DOI: https://doi. org/10.1037/a0025774. 
Hale, Adrian. 2018. "I Get It, But It's Just Not Funny": Why Humour Fails, After All Is Said and Done. - The European Journal of Humour Research 6 (1): 36-61. DOI: https://doi.org/10.7592/ EJHR2018.6.1.hale.

Janus, Samuel S. 1975. The Great Comedians: Personality and Other Factors. - The American Journal of Psychoanalysis 35 (2): 169-174. DOI: https://doi.org/10.1007/BF01358189.

Kalcik, Susan. 1975. “... Like Ann's Gynecologist or the Time I Was Almost Raped”: Personal Narratives in Women's Rap Groups. - The Journal of American Folklore 88 (347): 3-11. DOI: https:// doi.org/10.2307/539181.

Kuipers, Giselinde. 2006. Good Humor, Bad Taste: A Sociology of the Joke. Berlin: Mouton de Gruyter. DOI: https://doi.org/10.1515/9783110898996.

Kuipers, Giselinde. 2011. The Politics of Humour in the Public Sphere: Cartoons, Power and Modernity in the First Transnational Humour Scandal. - European Journal of Cultural Studies 14 (1): 63-80. DOI: https://doi.org/10.1177/1367549410370072.

Limon, John. 2000. Stand-up Comedy in Theory, or, Abjection in America. Durham, NC: Duke University Press. DOI: https://doi.org/10.2307/j.ctv1198z2t.

Lindfors, Antti. 2019a. Cultivating Participation and the Varieties of Reflexivity in Stand-Up Comedy. - Journal of Linguistic Anthropology 29 (3): 276-293. DOI: https://doi.org/10.1111/jola.12223.

Lindfors, Antti. 2019b. Intimately Allegorical: The Poetics of Self-Mediation in Stand-Up Comedy. PhD Dissertation. University of Turku. https://www.utupub.fi/handle/10024/147073 (accessed September 8, 2020).

Marsh, Moira. 2015. Practically Joking. Boulder, CO: University Press of Colorado. DOI: https:// doi.org/10.7330/9780874219845.

Marx, Nick. 2016. Expanding the Brand: Race, Gender, and the Post-politics of Representation on Comedy Central. - Television $\mathcal{E}$ New Media 17 (3): 272-287. DOI: https://doi. org/10.1177/1527476415577212.

Miles, Tim. 2014. No Greater Foe? Rethinking Emotion and Humour, With Particular Attention to the Relationship between Audience Members and Stand-up Comedians. - Comedy Studies 5 (1): 12-19. DOI: https://doi.org/10.1080/2040610X.2014.905093.

Norrick, Neal R. 1994. Involvement and Joking in Conversation. - Journal of Pragmatics 22 (3): 409-430. DOI: https://doi.org/10.1016/0378-2166(94)90117-1.

Oring, Elliott. 1984. Dyadic Traditions. - Journal of Folklore Research 21 (1): 19-28.

Oring, Elliott. 2003. Engaging Humor. Champaign, IL: University of Illinois Press.

Oring, Elliott. 2004. Risky Business: Political Jokes under Repressive Regimes. - Western Folklore 63 (3): 209-236.

Paton, George E.; Chris Powell, Luciano Venezia and Kelly Frailing. 1988. Humour in Society: Resistance and Control. Houndmills; London: Macmillan Press.

Quirk, Sophie. 2015. Why Stand-up Matters: How Comedians Manipulate and Influence. London; New Delhi: Bloomsbury Publishing. DOI: https://doi.org/10.5040/9781472578969.

Rutter, Jason. 1997. Stand-up as Interaction: Performance and Audience in Comedy Venues. A $\mathrm{PhD}$ dissertation. University of Salford. http://usir.salford.ac.uk/id/eprint/14688/ (accessed September 4, 2020).

Scarpetta, Fabiola and Anna Spagnolli. 2009. The Interactional Context of Humor in Standup Comedy. - Research on Language and Social Interaction 42 (3): 210-230. DOI: https://doi. org/10.1080/08351810903089159.

Seizer, Susan. 2011. On the Uses of Obscenity in Live Stand-Up Comedy. - Anthropological Quarterly 84 (1): 209-234. DOI: https://doi.org/10.1353/anq.2011.0001.

Smith, Moira. 2009. Humor, Unlaughter, and Boundary Maintenance. - The Journal of American Folklore 122 (484): 148-171. DOI: https://doi.org/10.1353/jaf.0.0080.

Stebbins, Robert A. 1990. Laugh-Makers: Stand-Up Comedy as Art, Business, and Life-Style. Montreal; Kingston: McGill-Queen's Press. 
Stewart, Simon and David R. Thompson. 2015. Does Comedy Kill? A Retrospective, Longitudinal Cohort, Nested Case-control Study of Humour and Longevity in 53 British Comedians. - International Journal of Cardiology 180: 258-261. DOI: https://doi.org/10.1016/j.ijcard.2014.11.152.

Titus, Christopher. 2004. Norman Rockwell Is Bleeding. - Youtube. https://www.youtube.com/ playlist?list=PL3zmJHEX37Qj_Pd5kG7ErFwShJt3wWBdX (accessed July 10, 2020).

Willis, Ken. 2005. Merry Hell: Humour Competence and Social Incompetence. - Beyond a Joke, edited by Sharon Lockyer and Michael Pickering. London: Palgrave Macmillan, 126-145. DOI: https://doi.org/10.1057/9780230236776_7.

Wilson, Glenn D.; John Rust and Judith Kasriel. 1977. Genetic and Family Origins of Humor Preferences: A Twin Study. - Psychological Reports 41 (2): 659-660. DOI: https://doi.org/10.2466/ pr0.1977.41.2.659.

Ziv, Avner and Orit Gadish. 1989. Humor and Marital Satisfaction. - The Journal of Social Psychology 129 (6): 759-768. DOI: https://doi.org/10.1080/00224545.1989.9712084.

Ziv, Avner. 2010. The Social Function of Humor in Interpersonal Relationships. - Society 47 (1): 11-18. DOI: https://doi.org/10.1007/s12115-009-9283-9.

Zoglin, Richard. 2009. Comedy at the Edge: How Stand-up in the 1970s Changed America. New York, NY: Bloomsbury Publishing USA.

\section{APPENDIX. QUESTIONNAIRE}

1. Do you often joke and laugh with your family members? Do you tell (or read) jokes to each other? Do you mention any funny stories that happened to you at work/when you go out in your family conversations?

2. Do you share jokes/funny pictures and videos digitally, and if yes, what kind of humorous content do you share? Can you cite any example of recently shared humour?

3. Do you make fun of your husband/wife/son/daughter/parents/siblings? Do they make fun of you? If you/they do what do you usually laugh at? Do you make fun of the appearance (hairstyle, clothes, a desire to get slimmer)? Do you make fun of some habit (snoring, eating habits, etc.)? Do you make fun of the speech (filler words, speaking too fast/slow, speaking emotionally, etc.)? Could you please cite any examples of jokes at each other's expense? How do you react when someone is making fun of you? How does your husband/wife/child reacts when someone makes fun of them?

4. Do you share some jokes and phrases with you wife/husband/... that only the two of you understand? Have there been any incidents that generated your personal idioms? If you have any, could you please cite any examples?

5. Do you use some humorous phrases from your favourite films/TV programmes/books? If you do, could you please cite any examples?

6. Do you share with you wife/husband... some humorous rituals and traditions that are related to getting up/going to bed, eating, meeting/parting, visits to the cinema/theatre/friends and family? If you do, could you please cite any examples?

7. Do you use some special funny gestures when you speak, walk, travel together, watch the movies, etc.? If you do, could you please cite any examples?

8. Do you use any funny forms of your names or nicknames when you speak to each other? Are there any names or nicknames that you use only on special occasions? If there are, could you please cite any examples?

9. Do you think the fact that you are a professional/amateur comedian influences your family communication? Why (not)? If it does, in what way? 